\title{
E-Integrated Marketing Communication and Its Impact on Customers' Attitudes
}

\author{
Suleiman A. Al Khattab" ${ }^{*}$, As'ad H. Abu-Rumman², Ghadeer Methqal Zaidan² \\ ${ }^{1}$ College of Business and Economics, Al Hussein Bin Talal University, Maan, Jordan \\ ${ }^{2}$ Department of Marketing, Applied Science Private University, Amman, Jordan \\ Email: Suliemanus@yahoo.com, Assd aborumman@asu.edu.jo
}

Received 16 July 2015; accepted 9 August 2015; published 12 August 2015

Copyright (C) 2015 by authors and Scientific Research Publishing Inc.

This work is licensed under the Creative Commons Attribution International License (CC BY).

http://creativecommons.org/licenses/by/4.0/

(c) (i) Open Access

\begin{abstract}
This study aims to investigate the impact of E-integrated marketing communication (E-IMC) on customers' attitudes toward electronic products. In order to achieve the objectives of the study, the researchers deployed the descriptive analytical approach due to its relevance to this kind of research. The sample was purposive random sample of online customers who were exposed to E-IMC in the context of electronic products in Jordan. 547 questionnaires were distributed; 498 questionnaires were collected back; and 455 questionnaires were accepted. The research included two main variables with sub dimensions; E-IMC as the independent variable, customers' attitudes toward electronic products representing the dependent variable. E-IMC sub dimensions were online advertising (OD), online public relations (OPR) and online sales promotion (OSP). Results revealed that there was a statistically significant relationship between E-integrated marketing communication (E-IMC) and customers' attitudes toward electronic products. In the light of the results, possible managerial implications are discussed and future research subjects are recommended.
\end{abstract}

\section{Keywords}

E-Integrated Marketing Communication (E-IMC), Customers' Attitudes, Electronic Companies, Jordan

\section{Introduction}

Fueled by technology advancements, the recent complete set of evolutionary trends in marketing has significantly led to the emergence and development of E-Integrated Marketing Communication (E-IMC). E-IMC has grown to be an important part of a company's promotional mix (Boutin, 2011) [1]; being a multi-faceted phe-

*Corresponding author.

How to cite this paper: Al Khattab, S.A., Abu-Rumman, A.H. and Zaidan, G.M. (2015) E-Integrated Marketing Communication and Its Impact on Customers' Attitudes. American Journal of Industrial and Business Management, 5, 538-547.

http://dx.doi.org/10.4236/ajibm.2015.58053 
nomenon that entitles a mix and synergies of all internet-based communications and is considered to be an expansion in itself of modes of distribution. E-IMC has multiplicity of well-recognized capacities and benefits such as low-cost, speed (instantaneous communication), geographic barrier reduction and efficiency (Thurau et al., 2010) [2]; (Kumar, 2012) [3]. This all strategically led organizations to positively adopt E-IMC characterized by a proactive-reactive attitude, consistency, continuity, flexibility and customization (Valos et al., 2010) [4].

This rapid pace of change in marketing communications has profoundly influenced customers' behavior as a whole and specifically customers' attitudes toward products in this evolving interactive market space (Ozuem et al., 2007) [5]. In summary, this research concerned itself with the impact of using E-IMC on customers' attitudes toward electronic products in Jordan, shedding light on online trust as a moderate variable. Understanding customers' responses to such emerging digital multi-communication multi-channel and multi-category environment helps firms in formulating better behavioral targeting strategies; that is to reach out customers based on where they are located and what their interests are. This dynamic research helps to understand how emerging media can augment traditional media. This is extremely critical for better management of customer relationships and development of strategies that aim at an effective allocation of budgeted promotional dollars through its dynamic impact on customers' attitudes, purchase incidence and quantity decisions.

Integrated Marketing Communication (IMC) has received almost instant recognition by the mid of the 1990s (Porcu et al., 2012) [6]. The factors that mainly interplayed leading to such escalating recognition were cost reduction apart from mass traditional advertising into a more personalized communication (Tetteh, 2015) [7]. Further reasons are fragmentation of media, customers and internet in addition to mobile technologies giving the advantage of a more centralized management as well as corporate message consistency (Winer, 2009) [8]. All previous factors leveraged this mode of communication not only to cultivate a deeper bond with customers and influencers but also to maximize return on investment (ROI) by integrating traditional marketing communications with E-IMC side by side (Kumar, 2012) [3]; (Morozan and Ciacu, 2012) [9].

The rapid development of internet, its acceptance and usage rate has been noted widely in the last ten years (Lovett, 2010) [10] reshaping and changing marketing communications leading to the creation of E-IMC as a major constituent discipline of IMC. The internet characteristics, interactivity, transparency and memory, have transformed the profile and behavior of online audiences into gaining more control than ever and a more proactive attitude (Gurau, 2008) [11]. The online audience is now more connected to the organization in an interactive two-way communication process (Valos et al., 2010) [4]. Not only that, but also more connected to each other, just a click away shedding the light on the role of electronic word of mouth in creating a positive or negative influence (Owen and Humphrey, 2009) [12]. It is absolutely true that audience has more access to information and they can easily pull information that suits their interest and needs.

Traditional IMC is theoretically pragmatic; what is meant is that on real grounds it does not fit easily into the organizational structure adopted by most firms (Percy, 1997) [13]. Of the most significant structural barriers to traditional IMC implementation are lack of budget and lack of database technology, escalating increase of markets' and media audiences' fragmentation, saturation of traditional media channels, new recurring marketing concepts like focal relationship marketing, in addition to internet users' acquisition of more control and power over the communication process due to prevalence of internet and recent advances in information technology (Fang et al., 2014) [14].

Because of these important realities for most companies in such a highly-competitive environment, there is a necessity to implement effectively and efficiently the concept of E-IMC integrated as part of IMC. It is considered as one of the best ways to encounter such difficulties. Internet is noticeably growing in use in Jordan; it is estimated by Telecommunication Regulatory Commission that internet users in Jordan are 5.7 million users (ALARABALYAWM, 2015) [15]. Jordan is ranked second in Internet usage in the Arab world (47 per cent), Around 84 per cent of Internet users in Jordan use the service every day, and also third in engagement in social networking sites among Arab states (JORDANTIMES, 2014) [16]. Nevertheless, E-IMC applications still face challenges in its application in the Arab World and specifically Jordan due to cultural constraints, customers' lack of knowledge competence in using the internet, lack of online trust, and lack of financial abilities to keep pace with technology advancements (electronic imports of Jordan declined 33.5\% in the first five months of 2014 (273.2 million JD) in sharp comparison with 2013 (410.9 million JD) (DOS.GOV, 2014) [17]. Other reasons are businesses' lack of horizontal communication, functional specialization, decentralization, lack of IMC planning and expertise, corporate culture and fear of change (Percy, 1997) [13]; (Al-Shoubaki, 2008) [18]. 
In this context, this study has investigated the impact of E-IMC on customers' attitudes toward electronic products specifically, whether positive or negative, that might eventually lead to purchase intentions and behavior.

\section{Literature Review}

Since the 1990s, integrated marketing communication (IMC) has gained prevalent significance as a strategic marketing management approach (Zavrsnik and Jerman, 2011) [19] due to the effectiveness of the integration of marketing communications tools (i.e. advertising, public relations, direct marketing, sales promotion and personal selling). This integration optimizes the communication impact on targeted customers (Vantamay, 2011) [20]. IMC adopts a holistic view of marketing communications with the objective of synergy of effects (Seric and Rijeci, 2012) [21]. IMC framework relies upon the deployment of multiple communication channels; inclusive of both traditional communications and E-integrated marketing communication (E-IMC), to enhance the contribution of each of them. It is rather a relational process and business competency at the same time. Its objective is to develop and maintain strong beneficial relationships with all stakeholders through ongoing two-way dynamic dialogue and communications. This will have its definite positive impact on sales and profits (Zavrsnik and Jerman, 2011) [19]. In other words, it is a move with main prints from traditional media to two way channels of communication (Tetteh, 2015) [7]. As for the term business competency; the capabilities of integrated management for various media channels help to reach superior results and synergistic outcomes (Chun et al., 2014) [22].

\subsection{E-Integrated Marketing Communication (E-IMC)}

E-IMC is a relatively new communication discipline that was declared to be a separate line of communication disciplines. Jensen and Jepsen (2006) [23] offered a new typology for E-IMC. A four-discipline model proposed including fifteen sub tools that were inferred from main works researchers studied. These four disciplines of E-IMC are online advertising, online public relations (PR), online sales promotions and online relationship communications. Integration and exploitation of all previous tools are essential to create value to grasp full E-IMC potential resulting in more holistic marketing communications. The study advised that E-IMC disciplines should be integrated with those of traditional IMC by finding the right mix, since E-IMC potential is very large if used in a targeted way. E-IMC characteristics by far surpass any offline media channel (Hoffman and Novak, 1996) [24]. E-IMC allows for all types of communication; to transmit information to customers, to provide consultation, to register click through as well as interact online. The researchers have treated E-IMC tools as one discipline due to their shared characteristics. These characteristics are freedom from temporal and spatial restrictions which means customers' accessibility to information without any geographical or temporal limitations. Moreover, E-IMC is about many-to-many communication, interactivity, hypertextuality, and personalization. Thus, all that definitely results in efficiency at a sustainable low cost. Jensen (2007) [25] suggested five-discipline model that included thirteen communication tools deduced. According to the researchers, E-IMC disciplines are online advertising, online relationship marketing, online interactive communication, online public relations (PR) and mobile communications. While Winer (2009) [8] acknowledged that media landscape has dramatically been affected in the early part of the $21^{\text {st }}$ century due to emergence of new technologies. The author aimed to provide an overview of this new media employed and stated some major measurement issues, problems, challenges and future research opportunities posed. Internet advertising had augmented all other established marketing tools used for the last fifty-one hundred years. Although traditional media is not disappearing, major marketers are shifting their spending into the new media categories. The new media is about interactivity, internet and digital media. Marketers are taking advantage of these new media channels to create targeted campaigns that can reach specific segments and engage customers to a much greater extent than traditional media (Ho et al., 2014) [26].

Alexandru and Carmen (2011) [27] investigated the main role online communication plays in relationship marketing. This was done among managers of Romanian tourism companies with the purpose of identifying the main online communication tools used to attract, keep and develop customers' long-term relationships in online environments. The researchers figured that although the notoriety of online marketing tools is high, some of these tools, known only by definition, are not used in practice and vice versa. They mentioned that online tools were classified depending on the purpose whether to attract or maintain customers. The study concluded that the most efficient online tools to attract customers are company's websites, search engines, sponsored links, 
e-newsletters, email marketing, social networks and online advertising. Whereas the most efficient online tools to maintain customers relationships are websites, e-newsletters, email marketing, social networks and instant messaging.

Morozan and Ciacu (2012) [9] have emphasized, that marketing communication is globalizing on the internet. This rapid adoption of new advanced technologies transformed production, distribution and consumption processes. The optimization of online channels must be deeply rooted and based on key performance indicators. Success is not guaranteed on the internet, it requires originality of products and ideas.

Rakic and Rakic (2014) [28] analyzed IMC integration through five aspects; media, communication methods, line of communication and possibilities of interaction, actors in addition to content creation. They emphasized that digital environment changed IMC. There is a shift towards digitization of communications and entire businesses. This kind of digitization is becoming a necessity for survival in the competitive environment. Not only there is digitization in communication, but also in customers and environment. Customization as a strategy offers additional competitive options in the overall marketing strategy and digitized world.

Online advertising: Jensen (2007) [25] classified online advertising into three primary sub tools. First, display advertising such as banners, pop-ups, and interstitials. Second, is search engine Optimization (SEO) or search engine marketing (SEM). SEO can be divided into organic and paid optimization. On one hand, SEO can give permanent high rankings and traffic, whereas SEA is a rather short term yet considered fast way to generate traffic. Third, are affiliate programs, are usually paid to the host on the basis of the number of leads converted into customers, pay-per-conversion, or by the number of leads referred.

Mohammed and AlKubise (2012) [29] also emphasize the importance of positive customers' attitudes toward websites in relation to the effectiveness of online advertising as well as trust in online contexts. Online trust is crucial as per study because of its effects on customers' purchasing intentions.

Online public relations $(P R)$ : PR is considered as always a tool to serve an as electronic brochure full of information needed. It is attractive due to its value, ability to acquire and overload information, short time span and availability all the time everywhere. Moreover, there are SEO and community building apparent in chatting rooms and discussion groups (Boutin, 2011) [1]. Huang et al. (2012) [30], categorized online PR into virtual press centre (VPC) which is easy to use as said by Haig and viral marketing. Viral marketing is a deliberate spreading of a message through online word-of-mouth. It can be carried in emails, streaming videos and audios, games, programs, websites, pictures or simple documents. Deodhar, (2014) [31] emphasized the tremendous potential of social networking sites (SNS's) as a marketing medium because of their interactivity, accessibility and efficiency. The author stressed that when used effectively, social media does strengthen relationships with core customers and increase profits.

Online sales promotion is the third major tool of E-IMC. Online sales promotion takes different forms such as electronic coupons, electronic samples, contest and sweepstakes. Al Shoubaki (2008) [18] stated that the goal is to increase traffic and build customer database On the other hand, Jensen (2007) [25] has classified what he called online interactive communications to include online coupons, online samples, contests and sweepstakes, microsites and games. These online sales promotion tools are usually used to encourage trial, involvement and repeated purchase, thus to increase sales.

\subsection{Customer Attitude}

There are so many studies that tackled customer attitude being a subject of high significance to marketers. Al-Alak and Al-Saed (2006) [32] investigated the impact of customers' attitudes toward website and whether these attitudes affect subsequent attitudes toward the brand and internet advertising. The researchers found that there is a definite positive impact on customers' attitudes toward brands seen on the internet through more brand recall and favorable views of the brand. According to the authors, customers need to be consulted about certain features of the website, and marketers must pre-test it before launch to increase its effectiveness. Jahangir and Begum (2007) [33] suggested a conceptual framework to study the impact of perceived usefulness, ease of use, security and privacy on Customer Attitude. They found out these variables are antecedents of customer attitude and they positively foster customer adaptation. Therefore, firms need to work on the development of positive beliefs on the customer's end. The authors also confirmed that customer attitude has a strong positive impact on customer's intention to behave being a mediator for customer adaptation.

Madhavaram and Appan (2010) [34] in their study found that the mainly focused on nonintrusive web-based 
marketing communications influenced more customers' explicit brand attitudes than implicit attitudes and vice versa. Second, organizations that focused primarily on intrusive web-based marketing communications had a positive effect on customers' impulse purchases through customers' implicit brand attitudes. Third, although customers' explicit attitudes toward intrusive web-based marketing communications were negative, consumers will hold positive implicit attitudes toward a well-known brand in sharp comparison with an unknown brand for a specific product. Huang et al. (2012) [30] confirmed that eWOM communications have a definite impact on customers' product attitudes and behavioral intentions. Customers rely on relationships with online communities to assess information quality. According to the above literature, the research model and the hypotheses have been prepared (Figure 1).

\subsection{The Main Hypothesis}

Ho.1: There is no significant impact of electronic integrated marketing communication (E-IMC) on customers' attitudes.

\section{Sub Hypotheses}

Ho.1.1: There is no significant impact of online advertising on customers' attitudes toward electronic products.

Ho.1.2: There is no significant impact of online public relations on customers' attitudes toward electronic products.

Ho.1.3: There is no significant impact of online sales promotion on customers' attitudes toward electronic products.

\section{Research Methodology}

The methodology used in this study is descriptive and analytical. The goal is to develop an appropriate method in order to achieve the objectives of this study which included a series of questions analyzed statistically to test the hypotheses of the research and made good use of many different literature references and sources to build a theoretical and practical background and research based on previous and new studies. Nominal, ordinal and Likert five scales are used to answer research questions and verify results achieved.

\subsection{Population and Sample of the Research}

The population of the study consists of all customers whom are exposed to IMC in the context of electronic products from all electronic companies in Jordan.

\subsection{Sample and Unit Analysis}

The sample consists of online customers whom are exposed to E-IMC in Jordan. The researchers distributed

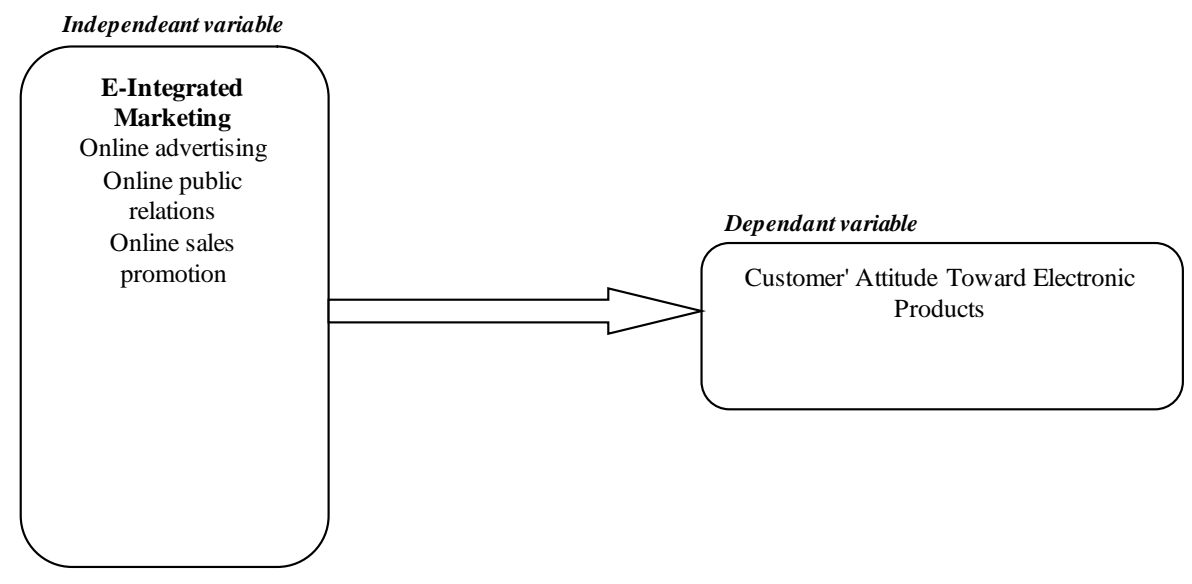

Figure 1. Research model. 
paper and online questionnaires to get sample responses. As for The unit sample (unit analysis); online customers whom are exposed to E-IMC in Jordan in the context of electronic products from all electronic companies, the sample that is used in this study is called purposive random sample and the criterion used to select unit sample (unit analysis) is to exposure E-IMC channels. The distributed number of responses was 547 questionnaires, 455 questionnaires were accepted. This sample was distributed in both online and traditional offline survey summarized in the Table 1 below.

In order to achieve the study objectives, a questionnaire was developed. Nominal, ordinal and Likert five scale were applied in the questionnaire and measurement of the study variables which was organized ranging from " 1 = strongly disagree" to " 5 = strongly agree". The questionnaire was developed to collect data from the sample of the study after reviewing some of the previous literature addressing each of the variables examined in the study, it contains three main questions, the first group is about demographic question, such as (age, gender, nationality, marital status, level of education, and work sector) about the study population, the second is about E-IMC which includes three sub domains and was covered by (15 questions): Online Advertising ( 5 questions), online public relations ( 5 questions), online sales promotion (5 questions). The third group is about customers' attitudes toward electronic products (5 questions).

\subsection{Reliability of the Study}

To declare the sincerity of the survey variables for the phenomenon being studied, study reliability was calculated that indicated the extent of reliance of measurement tool in giving the same results. This was done by using test pre-test method, in which the researchers applied the study tool on a sample of 60 customers of the sample, after three weeks the same or similar sample was tested again; the consistency degree was $90 \%$. To test the study reliability, Cronbach's alpha technique was used for this purpose, and its value for all of the domains was (94.9\%) as shown in Table 2.

\subsection{Descriptive Statics and Sampling Characteristics}

The descriptive statics includes the descriptive results of the sample, the unit of analysis, and the study variables statements. The sample was described by personal and functional factors based on online respondent's characteristics that are exposed to E-IMC in Jordan in the context of electronic products as shown in Table 3.

\subsection{Description of Study Variables}

Descriptive statistics, the researchers computed the means and standard deviations for all the study domains as shown in Table 4.

Table 1. Description of the questionnaire responses.

\begin{tabular}{cccc}
\hline Frequency percentage & No. of accepted questionnaires & No. of distributed questionnaires & Distribution method \\
\hline 47.47 & 216 & 291 & Online method \\
52.53 & 239 & 256 & Offline (traditional) method \\
100.0 & 455 & 547 & Total \\
\hline
\end{tabular}

Table 2. Reliability test using Cronbach alpha.

\begin{tabular}{|c|c|c|}
\hline Cronbach alpha & No. of items & Variables \\
\hline 0.903 & 20 & E-Integrated Marketing Communication (E-IMC) \\
\hline 0.826 & 5 & Online advertising \\
\hline 0.716 & 5 & Online public relations \\
\hline 0.774 & 5 & Online sales promotion \\
\hline 0.924 & 5 & Customers' attitudes toward electronic products \\
\hline 0.949 & 38 & All variables \\
\hline
\end{tabular}


Table 3. The frequencies and percentages on personal levels of the respondents.

\begin{tabular}{|c|c|c|c|}
\hline Percent & Frequency & \multicolumn{2}{|c|}{ Personal factors } \\
\hline 59.6 & 271 & Male & Gender \\
\hline 40.4 & 184 & Female & \\
\hline 0.9 & 4 & Less than 18 & Age (years) \\
\hline 39.1 & 178 & 18 - less than 28 & \\
\hline 43.1 & 196 & 28 - less than 38 & \\
\hline 11.6 & 53 & 38 - less than 48 & \\
\hline 4.4 & 20 & 48 - less than 58 & \\
\hline 0.9 & 4 & 58 years and above & \\
\hline 95.2 & 433 & Jordanian & Nationality \\
\hline 4.8 & 22 & Non Jordanian & \\
\hline 49.7 & 226 & Single & Marital status \\
\hline 46.6 & 212 & Married & \\
\hline 3.7 & 17 & Other & \\
\hline 3.7 & 17 & High school or less & Education \\
\hline 10.3 & 47 & Diploma & \\
\hline 64.2 & 292 & Bachelor & \\
\hline 21.8 & 99 & Higher studies & \\
\hline 10.3 & 47 & Public sector & Work sector \\
\hline 75.4 & 343 & Private sector & \\
\hline 14.3 & 65 & Not working & \\
\hline
\end{tabular}

From the previous Table 4 the mean range for all domains is from (3.4264) to (3.8985) referring to a degree of agreement, in which online public relations got the highest mean (3.8985) and standard deviation (0.70989), and the domain customer attitude with the lowest mean (3.4264) and standard deviation (0.86733).

\section{Testing the Study Hypotheses}

\subsection{The Main Hypothesis}

Ho.1: There is no significant impact of E-integrated marketing communication (E-IMC) on customers' attitudes toward electronic products.

Simple regression was performed and the results in Table 5 showed that the strength of the relation between the overall dimensions of E-integrated marketing communication (E-IMC) and customers' attitudes toward electronic products was $(\mathrm{R}=72.3 \%)$, and the coefficient of determination $\left(\mathrm{R}^{2}=0.522\right)$ which is an acceptable percentage, meaning that (52.2\%) of the total differences in the customers' attitudes toward electronic products is determined by E-integrated marketing communication (E-IMC), and the remaining percentage equal to (47.8\%) represents the contribution percentage of the excluded variables that were not included in the study model. The value of computed $(\mathrm{F}=494.842)$ which is higher than the tabular $\mathrm{F}$ at degree of freedom $(1-454)$ at significance level of (0.000). This indicates that the curve of regression is good in explaining the relation between E-integrated marketing communication (E-IMC) and customers' attitudes toward electronic products.

The results of simple regression analysis showed that there is a significant impact of the E-IMC on customers' attitudes toward electronic products, $(\beta=0.723)$ at level of significance $(0.000)$. 


\subsection{Sub-Hypotheses}

The results of the analysis (Table 6) showed that there is a significant impact of online advertising on customers' attitudes toward electronic products, $(\beta=0.251)$ at level of significance $(0.000)$. The results of the analysis showed that there is significant impact of online public relations on customers' attitudes toward electronic products, $(\beta=0.128)$ at level of significance (0.003). Also, the results of analysis showed that there is significant impact of online sales promotion on customers' attitudes toward electronic products, $(\beta=0.227)$ at level of significance (0.000).

\section{Findings and Discussion}

This study investigated the influential impact and relationship between E-Integrated Marketing Communication (E-IMC) and its channels in the electronics markets in Jordan with customers' attitudes toward electronic products. Based on the assumption o main hypothesis in addition to their sub hypotheses set the results of the research and rejects each hypothesis as per the answers of the questionnaire. Thus, the alternative hypotheses are correct and acceptable, which means that E-Integrated Marketing Communication (E-IMC) and its channels influence directly customers' attitudes toward electronic products.

The results showed that the most efficient and applicable channels of E-Integrated Marketing Communication (E-IMC) in the electronics markets in Jordan. The studied E-IMC channels were (Online advertising, online public relations and online sales promotion). This research concluded that each of the studied channels of E-IMC affect customers' attitudes toward electronic products having certain degrees of differences as shown in chapter four.

The results of the analysis showed that there is significant impact of E-IMC on customers' attitudes toward electronic products where $(\beta=0.723)$ at level of significance $(0.006)$. This result is attributed to the acknowledged reality that E-IMC in all its channels, if utilized effectively, can be a competitive edge on its own. Customization, personalization, targetability, accessibility, economic expansion with high reach, interactivity, engagement, cost-reduction, improvement of corporate image, significant increase on sales, and facilitation of

Table 4. Means and standard deviations for the study main domains.

\begin{tabular}{|c|c|c|c|}
\hline Agreement degree & Std. deviation & Mean & Item \\
\hline Medium & 0.57947 & 3.6427 & E-Integrated Marketing Communication (E-IMC) \\
\hline Medium & 0.70777 & 3.5785 & Online advertising \\
\hline High & 0.70989 & 3.8985 & Online public relations \\
\hline High & 0.62628 & 3.6985 & Online sales promotion \\
\hline Medium & 0.86733 & 3.4264 & Customers' attitude toward electronic products \\
\hline
\end{tabular}

Table 5. The impact of overall E-IMC on customers' attitudes toward electronic products.

\begin{tabular}{cccc}
\hline Sig & $\boldsymbol{T}$ & $\boldsymbol{B}$ & Independent variable \\
\hline $0.000^{*}$ & 22.245 & 0.723 & E-IMC \\
\hline
\end{tabular}

$\left(R=0.723 ; R^{2}=0.522 ; F=494.842\right) ;{ }^{*}$ Significant level at $P \leq 0.05$.

Table 6. The impact of E-IMC (dimensions) on customers' attitudes toward electronic products.

\begin{tabular}{cccc}
\hline Sig & $\boldsymbol{T}$ & $\boldsymbol{B}$ & Independent variable \\
$0.000^{*}$ & 5.773 & 0.251 & Online advertising \\
$0.006^{*}$ & 5.202 & 0.227 & Online sales promotion \\
$0.003^{*}$ & 3.021 & 0.128 & Online public relations \\
\hline
\end{tabular}

$\left(R=0.726 ; R^{2}=0.528 ; F=125.631\right) ;{ }^{*}$ Significant level at $P \leq 0.05$. 
communication process are of the many advantages of E-IMC exemplified in the synergy of all its channels. It is rather becoming a necessity these days. By analyzing the results of E-IMC channels, it shows that there is a significant impact of online advertising on customers' attitudes toward electronic products where $(\beta=0.251)$ at level of significance (0.000). In addition, the analysis of online public relations (OPR) shows the significant impact of OPR on customers' attitudes toward electronic products where $(\beta=0.128)$ at level of significance (0.003). The results of analysis also showed that online sales promotion (OSP) impacts significantly on customers' attitudes toward electronic products where $(\beta=0.227)$ at level of significance $(0.006)$, which also matches the results of (Jensen and Jepsen, 2007).

\section{Limitations of the Study and Suggestions for Future Research}

Marketers are recommended to enter into a coordinated constant dialogue with both internal and external audiences so as to get up-to-date feedback and evaluations of current and future potential channels, sub disciplines of E-IMC, and evaluation of their trustworthiness. In order to achieve utmost results, companies must adopt and integrate E-IMC into total IMC side by side, due to the acknowledged importance of both online and offline (tradition) marketing communications. Marketers need to further employ online trust enhancement techniques in a constant manner in online environments so that to open wider doors for E-IMC application, and to positively impact customers' attitudes, behavioral intentions, as well as actual behaviors as part of trust management both online and offline.

\section{References}

[1] Boutin, P.J. (2011) Mobile and Online Marketing Communications; Formulation of the Online Marketing Communications Mix: A Perspective Conceptual Model Based on Media Naturalness Theory. American Marketing Association, 22, 29-30.

[2] Thurau, T.H., Malthouse, E.C., Friege, C., Gensler, S., Lobschat, L., Rangaswamy, A. and Skiera, B. (2010) The Impact of New Media on Customer Relationships. Journal of Service Research, 13, 311-330. http://dx.doi.org/10.1177/1094670510375460

[3] Kumar, A. (2012) Managing Marketing Mix and Communications in a Digital Era: The Role Traditional and New Media in a Multichannel Environment. Unpublished PhD Thesis, University of Buffalo, New York.

[4] Valos, M.J., Ewing, M.T. and Powell, I.H. (2010) Practitioner Prognostications on the Future of Online Marketing. Journal of Marketing Management, 26, 361-376. http://dx.doi.org/10.1080/02672571003594762

[5] Ozuem, W., Howell, K.E. and Lancaster, G. (2007) Communicating in the New Interactive Marketspace. European Journal of Marketing, 42, 1059-1083. http://dx.doi.org/10.1108/03090560810891145

[6] Porcu, L., Garcia, S.D.B. and Kitchen, P.J. (2012) How Integrated Marketing Communications (IMC) Works? A Theoretical Review and Analysis of Its Main Drivers and Effects. Comunicación y Sociedad, 25, 313-348.

[7] Tetteh, V. (2015) Future of Integrated Marketing Communications. Research Starters Business, 1-77.

[8] Winer, R.S. (2009) New Communication Approaches in Marketing: Issues and Research Directions. Journal of Interactive Marketing, 23, 108-117. http://dx.doi.org/10.1016/j.intmar.2009.02.004

[9] Morozan, C. and Ciacu, N. (2012) Aspects of Online and Mobile Marketing. Economy Transdisciplinarity Cognition, 15, 191-199.

[10] Lovett, K.L. (2010) Integrated Marketing Communication and the Promotion of iPhone Application. Unpublished Master Thesis, Hawaii Pacific University, Hawaii.

[11] Gurau, C. (2008) Integrated Online Marketing Communication: Implementation and Management. Journal of Communication Management, 12, 169-184. http://dx.doi.org/10.1108/13632540810881974

[12] Owen, R. and Humphrey, P. (2009) The Structure of Online Marketing Communication Channels. Journal of Management and Marketing Research, 2, 54-62.

[13] Percy, L. (1997) Strategies for Implementing Integrated Marketing Communication. NTC Business Books, Chicago.

[14] Fang, Y., Qureshi, I., Sun, H. and McCole, P. (2014) Trust, Satisfaction, and Online Repurchase Intention: The Moderating Role of Perceived Effectiveness of E-Commerce Institutional Mechanism. MIS Quarterly, 38, 407-427.

[15] AlARABALYAWM (2015) https://www.alarabalyawm.net

[16] JORDANTIMES (2014) https://jordantimes.com

[17] Department of Statistics in Jordan (2014) http://www.dos.gov.jo 
[18] Al Shoubaki, O. (2008) The Extent of Using E-Integrated Marketing Communication Tools and Their Effect on the Export Performance of Jordanian Companies (Exploratory Study). Unpublished Master’s Thesis, University of Jordan, Amman.

[19] Zavrsnik, B. and Jerman, D. (2011) Measuring Integrated Marketing Communication. Scientific Annals of the "Alexandru Loan Cuza" University of Lasi, 351-361.

[20] Vantamay, S. (2011) Performances and Measurement of Integrated Marketing Communications (IMC) of Advertisers in Thailand. Journal of Global Management, 1, 1-12.

[21] Seric, M. and Rijeci, K. (2012) Integrated Marketing Communications in High-Quality Hotels of Central and Southern Dalmatia: A Study from the Perspective of Managers and Guests. Trziste, 24, 67-83.

[22] Chun, K.Y., Song, J.H., Hollenbeck, C.R. and Lee, J.H. (2014) Are Contextual Advertisements Effective? The Moderating Role of Complex in Banner Advertising. International Journal of Advertising, 33, 351-371. http://dx.doi.org/10.2501/IJA-33-2-351-371

[23] Jensen, M.B. and Jepsen, A.L. (2006) Online Marketing Communications: Need for a New Typology for IMC? Journal of Website Promotion, 2, 19-35.

[24] Hoffman, D.L. and Novak, T.P. (1996) Marketing in Hypermedia Computer-Mediated Environments: Conceptual Foundations. Journal of Marketing, 60, 50-68. http://dx.doi.org/10.2307/1251841

[25] Jensen, M.B. (2007) Online Marketing Communication Potential: Priorities in Danish Firms and Advertising Agencies. European Journal of Marketing, 42, 502-525.

[26] Ho, S.Y. and Bodoff, D. (2014) The Effects of Web Personalization on User Attitude and Behavior: An Integration of the Elaboration Likelihood Model and Consumer Search Theory. MIS Quarterly, 38, 479-520.

[27] Alexandru, P.N. and Carmen, A. (2011) A Qualitative Research Regarding the Marketing Communication Tools Used in the Online Environment. Annals of the University of Oradea, Economic Science Series (2011 Supplement), 119-125.

[28] Rakic, B. and Rakic, M. (2014) Integrated Marketing Communications Paradigm in Digital Environment: The Five Pillars of Integration. Megatrend Review, 11, 187-204. http://dx.doi.org/10.5937/MegRev1401187R

[29] Mohammed, A.B. and AlKubise, M. (2012) How Do Online Advertisements Affect Consumer Purchasing Intention: Empirical Evidence from a Developing Country. European Journal of Business and Management, 4, 208-218.

[30] Huang, J.-H., Hsiao, T.-T. and Chen, Y.-F. (2012) The Effects of Electronic Word of Mouth on Product Judgment and Choice: The Moderating Role of the Sense of Virtual Community. Journal of Applied Social Psychology, 42, 23262347. http://dx.doi.org/10.1111/j.1559-1816.2012.00943.x

[31] Deodhar, M. (2014) To Like or Not to Like: When Social Media Marketing Is Effective. Unpublished Bachelor’s Thesis, Robert D. Clark Honors College, Eugene.

[32] Al-Alak, B.A. and Al-Saed, R.M. (2006) Measuring the Effectiveness of Internet Advertising in Jordan (A Field Study). Jordan Journal of Business Administration, 2, 317-325.

[33] Jahangir, N. and Begum, N. (2007) Effect of Perceived Usefulness, Ease of Use, Security and Privacy on Customer Attitude in the Context of E-Banking. Journal of Management Research, 7, 147-157.

[34] Madhavaram, S. and Appan, R. (2010) The Potential Implications of Web-Based Marketing Communications for Consumers’ Implicit and Explicit Brand Attitudes: A Call for Research. Psychology \& Marketing, 27, 186-202. http://dx.doi.org/10.1002/mar.20326 